\title{
The effect of flow data resolution on sediment yield estimation and channel design
}

Tyler T. Rosburg ${ }^{\mathrm{a}}$, Peter A. Nelson, Ph.D., ${ }^{a}$ Joel S. Sholtes, Ph.D., ${ }^{a}$ Brian P. Bledsoe, Ph.D.,

a'Department of Civil and Environmental Engineering, Colorado State University, 1372 Campus Delivery, Fort Collins, CO, USA 80523

${ }^{b}$ College of Engineering, University of Georgia, Athens, GA, USA 30602

*Corresponding author. Email Address: tyler.rosburg@ gmail.com

(C) 2016. This manuscript version is made available under the Elsevier user license http://www.elsevier.com/open-access/userlicense/1.0/ 
KEYWORDS: sediment yield, half-load discharge, daily-averaged, sub-daily flow data, channel design, stream flashiness. 


\section{ABSTRACT}

The decision to use either daily-averaged or sub-daily streamflow records has the potential to impact the calculation of sediment transport metrics and stream channel design. Using bedload and suspended load sediment transport measurements collected at 138 sites across the United States, we calculated the effective discharge, sediment yield, and half-load discharge using sediment rating curves over long time periods (median record length $=24$ years) with both dailyaveraged and sub-daily streamflow records. A comparison of sediment transport metrics calculated with both daily-average and sub-daily stream flow data at each site showed that dailyaveraged flow data do not adequately represent the magnitude of high stream flows at hydrologically flashy sites. Daily-average stream flow data cause an underestimation of sediment transport and sediment yield (including the half-load discharge) at flashy sites. The degree of underestimation was correlated with the level of flashiness and the exponent of the sediment rating curve. No consistent relationship between the use of either daily-average or sub-daily streamflow data and the resultant effective discharge was found. When used in channel design, computed sediment transport metrics may have errors due to flow data resolution, which can propagate into design slope calculations which, if implemented, could lead to unwanted aggradation or degradation in the design channel. This analysis illustrates the importance of using sub-daily flow data in the calculation of sediment yield in urbanizing or otherwise flashy watersheds. Furthermore, this analysis provides practical charts for estimating and correcting these types of underestimation errors commonly incurred in sediment yield calculations. 


\section{INTRODUCTION}

Current practice in stable channel design focuses on a single "channel forming" discharge that is assumed to be the flow primarily responsible for performing work, transporting sediment, and shaping channel geometry over a period of years (Soar and Thorne, 2001; Doyle et al., 2007). Coupling continuous flow series with sediment-transport relationships to quantify the combined effects of flow and sediment regime using magnitude-frequency analysis (Wolman and Miller,1960) is increasingly used to compute physically based estimates of channel forming flows, such as the effective discharge (e.g., Shields et al., 2003; Doyle et al., 2007) or the halfload discharge (Sholtes and Bledsoe, 2016).

Sediment yield estimates used in alluvial channel design are calculated from two types of input data: relations between stream discharge and the sediment transport rate, and flow frequency distributions. The accuracy of a sediment yield calculation will therefore be determined by the errors or uncertainties in these two components. The relationship between discharge and sediment transport is often characterized via a sediment rating curve, which is an empirical best-fit power function relating paired instantaneous streamflow and sediment discharge measurements (Walling, 1977). Errors and limitations of sediment rating curves have been extensively studied: for example, they can be imperfect estimators of sediment transport rates due to statistical fitting errors (Ferguson, 1987), storm event hysteresis (Walling, 1977; Moog and Whiting, 1998), non-stationarity in sediment supply over time (Asselman, 2000), and fluctuations inherent to sediment transport (e.g., Kuhnle and Southard, 1988; Curran et al., 2015). Uncertainty in sediment yield calculations due to the flow frequency distribution characteristics, however, has received little attention. In particular, it is not known how the 
resolution of a streamflow dataset (i.e., daily-averaged vs. sub-daily measurements) can affect sediment yield calculations.

The use of daily-averaged streamflow records paired with sediment rating curves to calculate sediment yield implicitly assumes that this resolution of data adequately represents the flow regime. However, studies have shown that small (Ågren et al., 2007), urban (Graf, 1977; Walsh et al., 2005), and arid watersheds (Allan and Castillo, 2007) can exhibit rapid short-term variations in streamflow during runoff events. This type of streamflow behavior is termed “flashy." In flashy watersheds, flows that transport high sediment loads may happen infrequently and for very brief periods of time; in these situations, daily-averaged flow data may not adequately capture the magnitude of discharge most important for sediment transport.

It was recognized long ago that using sediment rating curves with daily-averaged flow data could cause errors in the computation of sediment discharge if the daily-average stream discharge is not representative of the flow rate throughout the day (Colby, 1956). Because sediment discharge is nonlinearly related to stream discharge, small errors in the magnitude of streamflow may cause large errors in the estimation of sediment transport. However, quantitative relationships between flow regime characteristics such as flashiness, characteristics of the sediment transport rating curve, and the relative error in sediment transport metrics due to flow data resolution have not been established. We hypothesize that errors in sediment transport and yield calculations based on daily-average flow data systematically increase with stream flashiness.

There have been few studies exploring how flow data resolution can affect sediment yield calculations. A study of six watersheds in East Devon, England showed that sediment yield 
calculations from daily flow records could vary by up to $10 \%$ from those made with instantaneous records (Walling, 1977). A study of small to medium-size watersheds (smaller than $620 \mathrm{~km}^{2}$ ) of the Yazoo River basin in Northwest Mississippi revealed that sediment yield curves created from daily-averaged flow data can deviate from 15-minute sediment yield curves by more than $100 \%$ (Hendon, 1995). This was because the highest discharges, occurring less than $3 \%$ of the time, were smoothed out in the daily-averaged data. In another study from the same basin, use of daily-average flow data were found to underpredict sand yield by $51 \%$ and total suspended sediment yield by 59\% (Dubler, 1997). To the best of our knowledge, the effect of flow data resolution on sediment transport calculations has not been investigated anywhere else.

In this paper, we explore the effect of flow data resolution on sediment transport metrics for both bedload and suspended load transport for fine and coarse bed rivers across the United States. The objectives of this paper are: (i) to quantify the effect of flow data resolution (dailyaveraged and sub-daily) on sediment yield calculations; (ii) to investigate the factors such as hydrologic flashiness or sediment rating curve characteristics that most strongly influence the error in calculating sediment yield metrics so that we may better understand under what conditions it is important to have sub-daily flow data, iii) to provide readers the necessary tools to self-identify situations in which using daily-averaged flow data for sediment transport calculations is, or is not acceptable based on their own specifications; and (iv) to investigate the potential impacts on channel design parameters when daily-averaged flows are used in situations where sub-daily flows are more appropriate. 


\section{METHODS}

\subsection{DATA SELECTION}

This analysis draws on sediment transport data and flow records that were that were assembled for a related study concerning the magnitude and frequency of sediment transport in U.S. streams and rivers (Sholtes, 2015). Sites used in this analysis have > 15 measurements of sediment load and instantaneous discharge collected adjacent to a stream gage with a long term record (median record length $=24$ years) of daily and sub-daily discharge data. In total, 39 sites with bedload data and 99 sites with suspended sand load data were included in this analysis (Figure 1).

The sites cover a wide range of the conterminous United States and represent drainage areas ranging from approximately 10 to $2,500,000 \mathrm{~km}^{2}$. Basins were chosen such that a wide range of flow regimes would be analyzed including flashy and non-flashy systems. Summary information for sites used in the present study can be found in Tables S1 and S2 in the supplementary materials.

All bedload data were collected using Helley-Smith bedload samplers as this type of sampler has been the most widely used within the U.S., and the vast majority of existing bedload data were collected with this device. Suspended load data were retrieved from the USGS Sediment Data Portal (http://cida.usgs.gov/sediment), an on-line database of suspended sediment measurements for sites across the U.S. Bedload data are used to represent sediment transport in coarse bed rivers with median bed material grain sizes $>4 \mathrm{~mm}$ (gravel and larger) at sampling sites. Suspended sand load $(>0.0625 \mathrm{~mm})$ measurements are used to represent sediment transport in sand bed rivers with median bed material grain sizes $\leq 1 \mathrm{~mm}$. These sites are referred to as bedload and suspended load sites based on the data used to represent sediment transport within them. Fine bed sites are scattered geographically and have a range of flow regimes, whereas 
coarse bed sites are clustered in the U.S. Rocky Mountain and Northwest regions due to lack of concurrent bed load and stream gage data elsewhere. Flow regimes for coarse bed sites are mostly snow-melt dominated, though some flashier systems are represented in the data from the Pacific Coast and Southwest regions of the U.S. (Figure 1).

Figure 1: Map of sites used in this study.

Daily flow data and sub-daily flow data (after Oct. 1, 2007) were obtained from USGS National Water Information System (http://www.waterdata.usgs.gov/nwis) website. Sub-daily flow data (prior to Oct. 1, 2007) were obtained through the USGS Instantaneous Data Archive (http://www.ida.water.usgs.gov/ida). The record length of flow data retrieved varied by site but ranged from the first day in which sub-daily flow data were available through the water year 2013, if possible. However, some gages were discontinued prior to 2013. In total, 80 percent of sites used in this analysis contained more than 10 years of flow data.

Flow data downloaded from the USGS were filtered prior to analysis. All blank observations and observations of "ice" were removed. Additionally, due to discontinuities in both the daily and sub-daily flow data, the flow data were filtered to ensure that the period of record of both datasets were identical. For some sites, the sub-daily flow data included a mix of observations recorded at 15 minute and one hour intervals. To ensure consistent flow data resolution for our analysis, all sub-daily flow data were sampled on the top of the hour to create a consistent set of hourly observations.

\subsection{HYDROLOGIC FLASHINESS}


We hypothesized that sub-daily flow data would be most accurate in estimating sediment yield for hydrologically flashy systems because daily-averaged flow data do not adequately represent the flow regime. Stream flashiness was calculated with daily-averaged flow data at each site. Daily-averaged flow, as opposed to sub-daily flow data, was used to quantify flashiness because daily-averaged data are the most commonly available streamflow data and flashiness calculations, therefore, need not be limited to sites with sub-daily flow data. Several methods have been proposed for quantifying stream flashiness (Baker et al., 2004; Konrad and Booth, 2002), and most flashiness metrics are well correlated (Sholtes, 2015). Here we use the Richards-Baker flashiness index (Baker et al., 2004):

$$
R B=\frac{\sum_{i=1}^{n}\left|q_{i}-q_{i-1}\right|}{\sum_{i=1}^{n} q_{i}} .
$$

Here, $R B$ is the Richards-Baker flashiness index, $q_{i}$ is the daily-averaged discharge on day $i$, and $n$ is the total number of days in the flow record. $R B$ calculates the ratio of the sum of the absolute values of day-to-day changes in discharge to the sum of mean daily flows. The $R B$ index is high for sites characterized by large inter-daily variability in discharge.

\subsection{SEDIMENT RATING CURVES}

Relationships between water discharge and sediment load may often take the form of a simple power function: $Q_{s}=a Q^{b}$, where $Q_{s}$ is the sediment discharge rate $(\mathrm{kg} / \mathrm{s}), Q$ is the concurrently-measured water discharge rate $\left(\mathrm{m}^{3} / \mathrm{s}\right)$, and $a$ and $b$ are best fit regression parameters (Asselman, 2000, Syvitski et al., 2000). This function is referred to as a sediment rating curve. In this relationship, it has been suggested that the exponent $b$ is related to the transport capacity in excess of sediment supply within a river channel, while the coefficient $a$ is related to absolute 
sediment supply (Barry et al., 2004). The exponent, $b$, tends to increase with the size of bed material in coarse bed rivers (Emmett and Wolman, 2001).

To estimate the parameters of the sediment rating curve, both the water and sediment transport data were log-transformed as they are heteroscedastic. We fit the log-log models using the $\operatorname{rlm}()$ function in the MASS package (Venables and Ripley, 2002) in R (R Core Team, 2014). This is a robust linear regression method that is less sensitive to outliers than ordinary least squares (OLS) regression, and does not require residuals to be normally distributed (though is does require residuals to be symmetric). To correct for transformation bias when un-transforming the parameters, the multiplicative bias correction factor discussed by Ferguson (1987) was used. All log-log slopes ( $b$ values) are significant using an approximation of normality test calculated with the $\operatorname{lm} \operatorname{Rob}()$ function in the robust package in $\mathrm{R}$ (Wang et al., 2014) (maximum $p=0.019$ ). Multiple $\mathrm{R}^{2}$ values from these robust linear models are calculated from the weighted residuals from the robust linear models and ranged from 0.25 to 0.79 (median $=0.59$ ); however, $76 \%$ of these values are greater than or equal to 0.5 . These multiple $\mathrm{R}^{2}$ values are lower than the conventional $\mathrm{R}^{2}$ values derived from OLS regression. For comparison, values of $\mathrm{R}^{2}$ from OLS regression range from 0.22 to $0.96($ median $=0.75)$ with $94 \% \geq 0.5$.

\section{SEDIMENT TRANSPORT METRICS}

To characterize sediment discharge at each site, three sediment transport metrics were calculated using both the daily averaged and the sub-daily flow data. The sediment transport metrics utilized in this study are the effective discharge $\left(Q_{E f f}\right)$, the discharge below which $50 \%$ of the bed material load is transported on average $\left(Q_{s 50}\right)$, and the sediment yield $(S Y)$ (Figure 2).

$Q_{E f f}$ refers to the increment of discharge that transports the largest fraction of the annual sediment load over a period of years (Andrews, 1980). For some streams and rivers, $Q_{E f f}$ is often 
considered to be the "channel forming discharge" and nearly equivalent to bankfull discharge (Andrews, 1980; Doyle et al., 2007, Soar and Thorne, 2013). To compute $Q_{E f f}$, the sediment rating curve (green curve in Figure 2) is multiplied by the flow frequency curve (blue curve in Figure 2) to produce a sediment yield curve (red curve in Figure 2), which represents the average amount of sediment transported by each flow rate over the period of record. $Q_{E f f}$ is the flow corresponding to the peak of the sediment yield curve.

In practice, the effective discharge is generally computed by first subdividing the range of streamflows observed during a period of record into a number of classes or bins from which the total sediment quantity transported by each class is calculated. This is achieved by multiplying the frequency of flow occurrence in each class by the median sediment load for that flow class (Biedenharn et al., 2000) estimated from a sediment rating curve. This procedure results in a series of discrete product values that form an effectiveness curve, with $Q_{E f f}$ being the flow corresponding to the discharge of the flow class with the maximum sediment yield, or peak of this product curve.

Figure 2: Qualitative illustration of sediment transport metrics used in this study. The procedure by which the flow record is binned into a histogram to approximate the flow frequency curve can influence the computed $Q_{E f f} . Q_{E f f}$ has been calculated using bins spaced both arithmetically and logarithmically, with most analyses using arithmetic bins (Soar and Thorne, 2001). In this study, we initially divided the flow records at each site into 25 arithmetic bins (e.g., Biedenharn et al., 2000), and this streamflow frequency histogram was multiplied by the sediment rating curve to create a sediment yield curve. If the resulting $Q_{E f f}$ fell into the first 
bin, the first bin was subdivided into three new bins and the analysis was repeated. This was done to prevent the under-estimation of $Q_{E f f}$. If $Q_{E f f}$ fell into the first bin again, the original first bin was subdivided into 5 bins. This process was repeated until $Q_{E f f}$ no longer occurred in the first bin or until the original first bin has been subdivided into 11 or more bins. Once the bin with the maximum sediment yield was identified, the median flow in that bin was considered $Q_{E f f}$.

We performed trapezoidal numerical integration using the trapz function in the PRACMA package (Borcher, 2015) in R on the sediment yield curve (red line, Figure 2) to compute the total sediment yield $(S Y)$ for the multi-year period of record. Sediment yield is graphically depicted as the area under the red line in Figure 2.

Lastly, to calculate the half-load discharge $\left(Q_{s 50}\right)$, an ordered vector of sediment discharges was created by sorting the water discharges and applying the sediment rating curve. The ordered sediment discharge vector was then cumulatively summed and normalized to a fraction of the cumulative sediment yield. $Q_{s 50}$ was then determined by locating the water discharge that corresponded to $50 \%$ of the cumulative sediment transport, $Q_{s 50}$, which can be greater than or less than $Q_{E f f}$ depending on the shape of the sediment yield curve.

\subsection{Sediment Yield - Flashiness Relationship}

We used quantile regression and multi-variate linear regression to investigate the effect of flow data resolution on sediment yield metrics $Q_{E f f} S Y$, and $Q_{s 50}$. The response variables in these analyses are the ratios of the sediment transport metrics computed from daily-averaged flow data to those which were computed with sub-daily flow data. Sediment yield estimates made with sub-daily flow data are more accurate in general than estimates made with daily-averaged data due to the nonlinear relationship between sediment transport and discharge. Therefore, we 
consider the sediment yield metrics computed with sub-daily data to be reference values against which metrics computed with daily-averaged flow data can be compared. We refer to the differences between metrics computed using daily and sub-daily flows (expressed as ratios $S Y_{\text {Daily }} / S Y_{S u b}, Q_{E f f-D a i l y} / Q_{E f f-S u b}$, and $\left.Q_{s 50-D a i l y} / Q_{s 50-S u b}\right)$ as “errors", although it is important to acknowledge that even metrics computed with sub-daily flow data are not likely to be completely accurate.

\subsubsection{QUANTILE REGRESSION}

Quantile regression (Koenker and Bassett, 1978) was used to analyze the relationships between our response variables $\left(S Y_{\text {Daily }} / S Y_{S u b}, Q_{E f f-D a i l y} / Q_{E f f-S u b}, Q_{\text {s50-Daily }} / Q_{s 50-S u b}\right)$ and $R B$ flashiness. While most regression applications estimate rates of change in the mean of the response variable, quantile regression estimates rates of change for all portions of a probability distribution of the response variable (Cade and Noon, 2003). Quantile regression is especially useful for regression models with heterogeneous variances, as ordinary regression techniques may underestimate, overestimate, or fail to identify real changes in the heterogeneous distribution (Cade and Noon, 2003).

\subsubsection{MULTI-VARIATE LINEAR REGRESSION}

Multi-variate linear regression was utilized to model relationships between the response variables and a group of predictor variables and their interactions. The predictor variables included in the analysis were $R B$, average annual precipitation derived from 30-year normals (PRISM Group, 2015), watershed drainage area, median bed sediment size $\left(D_{50}\right)$, the $84^{\text {th }}$ percentile of bed sediment size $\left(D_{84}\right)$, the best-fit sediment rating curve exponent $(b)$, and the best-fit sediment rating curve coefficient $(a)$. The best regression subsets using 1 and 2 predictor variables and their interaction were identified using the regsubsets function in the LEAPS 
package (Lumley and Miller, 2009) in R. Predictor variables identified in each best subset were checked for cross-correlation before being regressed, and a maximum $\mathrm{R}^{2}$ value of 0.20 was allowed amongst variables in a regression model.

\section{RESULTS}

\subsection{EFFECTIVE DISCHARGE}

The hydrologic flashiness at a river station as quantified by $R B$ did not systematically influence the ratio of effective discharge computed with daily-averaged flow data $\left(Q_{E f f-D a i l y}\right)$ to that computed with sub-daily flow data $\left(Q_{E f f-S u b}\right)$ (Figure 3$)$. Of the bedload sites, approximately $60 \%$ had a $Q_{E f f-D a i l y} / Q_{E f f-S u b}$ ratio that was larger than unity. Similarly, of the suspended load sites, $40 \%$ had a $Q_{E f f-D a i l y} / Q_{E f f-S u b}$ ratio that was larger than unity. The ratio of $Q_{E f f-D a i l y} / Q_{E f f-S u b}$ tended to be greater than unity for flashy bedload sites $(R B>0.3)$. Flashiness also appeared to be related to error in $Q_{E f f-D a i l y}$ for suspended load sites. As $R B$ flashiness increases, the departure of

$Q_{E f f-D a i l y} / Q_{E f f-S u b}$ from unity increased. Because no strong relationship between $R B$ and $Q_{E f f-D a i l y} /$ $Q_{E f f-S u b}$ was observed, we proceeded with additional regression analyses only with the other sediment yield metrics: $S Y_{\text {Daily }} / S Y_{S u b}$ and $Q_{s 50-D a i l y} / Q_{s 50-S u b}$

Figure 3: Ratio of effective discharge computed with daily-averaged flow to sub-daily flow vs. the Richards-Baker flashiness index: a) bedload sites b) suspended load sites. 


\subsection{QUANTILE REGRESSION}

\subsubsection{Sediment Yield}

Sediment yield computed with daily-averaged flow data $\left(S Y_{\text {Daily }}\right)$ was found to generally be less than sediment yield computed with sub-daily flow $\left(S Y_{S u b}\right)$ (Figure 4). The ratio of $S Y_{\text {Daily }} /$ $S Y_{S u b}$ was found to decrease with flashiness in a wedge-shaped fashion for both bedload and suspended load sites. That is, for non-flashy sites $(R B \approx 0.1), S Y_{D a i l y} / S Y_{S u b}$ was nearly equal to unity while for flashy sites $(R B>0.4), S Y_{D a i l y} / S Y_{S u b}$ was found to range from 0.4-1. Quantile regression was used to further investigate the relationship of $S Y_{D a i l y} / S Y_{S u b}$ to flashiness. The various "quantile" lines represent the relationships of the 5th, 25th, 50th, 75th, and 99th percentiles of the $S Y_{\text {Daily }} / S Y_{\text {Sub }}$ distribution to flashiness (Figure 4).

Increased variance in the regression of $S Y_{\text {Daily }} / S Y_{S u b}$ and $Q_{s 50-D a i l y} / Q_{s 50-S u b}$ with $R B$ flashiness index was observed for sites with a greater magnitude of the sediment rating curve parameter $b$. For the flashiest suspended load sites with $R B>0.6$, as $b$ increases, the ratio of $S Y_{\text {Daily }} / S Y_{\text {Sub }}$ decreases (

Figure 5). There is not a strong correlation between $b$ and $Q_{s 50-D a i l y} / Q_{s 50-S u b}\left(R^{2}=0.17\right)$.

Figure 4: Ratio of sediment yield computed with daily-averaged flow to sub-daily flow vs. the Richards-Baker flashiness index: a) bedload sites b) suspended load sites.

Figure 5: Relationship between the underestimation of $S Y, Q_{s 50}$, and the sediment rating curve best fit exponent, $b$, for suspended load sites with a $R B$ flashiness greater than 0.6. 


\subsubsection{Half-load discharge $\left(Q_{s 50}\right)$}

The value of the half-load discharge calculated with daily flow data $\left(Q_{s 50-D a i l y}\right)$ was generally less than its sub-daily flow counterpart $\left(Q_{s 50-S u b}\right)$ (Figure 6). Much like the $S Y$ data, the $Q_{s 50}$ data formed a wedge-shaped pattern in which the sediment rating curve parameter $b$ influenced the degree of response of $Q_{s 50-D a i l y} / Q_{s 50-S u b}$. That is, for non-flashy sites $(\mathrm{RB} \approx 0.1)$, $Q_{s 50-D a i l y} / Q_{s 50-S u b}$ was nearly equal to unity, while for flashy sites (RB $\left.>0.4\right), Q_{s 50-D a i l y} / Q_{s 50-S u b}$ ranged from 0.2-1. Just as we observed in the $S Y_{\text {Daily }} / S Y_{S u b}$ results, the sediment rating curve parameter $b$ contributed to the degree of response of $Q_{s 50-D a i l y} / Q_{s 50-S u b}$ to flashiness. For sites with flashy flow characteristics, as rating curve parameter $b$ increased, the ratio of $Q_{s 50-D a i l y} / Q_{s 50-}$ Sub decreased (Figure 5).

Figure 6: Ratio of discharge below which $50 \%$ of sediment is transported computed with dailyaveraged flow to sub-daily flow vs. the Richards-Baker flashiness index: a) bedload sites b) suspended load sites

\subsection{MULTI-VARIATE LINEAR REGRESSION ANALYSIS}

Table 1 presents the best predictors of change in $S Y_{\text {Daily }} / S Y_{S u b}$ and $Q_{s 50-D a i l y} / Q_{s 50-S u b}$ as determined from the best subsets analysis of the multi-variate linear regression procedure. $R B$ was found to be the best single predictor of change in both in $S Y_{\text {Daily }} / S Y_{S u b}$ and $Q_{s 50-D a i l y} / Q_{s 50-S u b}$ for both bedload and suspended load sites as it explained more variance than any other single variable (i.e., higher $\mathrm{R}^{2}$ value). The second- and third-best indicators for all models were $b$ and $D_{50}$. The model with the highest adjusted $\mathrm{R}^{2}$ was a 2-variable interaction model in which $R B$ and $b$ are the independent variables. All models in Table 1 are significant at $p<0.0001$. 
Table 1: Multi-variate linear regression models for the prediction of $S Y_{\text {Daily }} / S Y_{S u b}$ and $Q_{s 50-D a i l y} /$ $Q_{s 50-S u b}$ for suspended and bedload sites.

\begin{tabular}{|c|c|c|c|c|}
\hline $\begin{array}{c}\text { Bedload / Suspended } \\
\text { Load }\end{array}$ & $\begin{array}{l}\text { Dependent } \\
\text { Variable }\end{array}$ & $\begin{array}{c}\text { Number of } \\
\text { independent } \\
\text { variables }\end{array}$ & Best Regression Model & Adj. $R^{2}$ \\
\hline Bedload & $\mathrm{SY}_{\text {Daily }} / \mathrm{SY}_{\text {Sub }}$ & 1 & $1.02-0.45 \mathrm{RB}$ & 0.37 \\
\hline Bedload & $Q_{s 50-D a i l y} / Q_{s 50-S u b}$ & 1 & $1.03-0.55 R B$ & 0.38 \\
\hline Suspended Load & $\mathrm{SY}_{\text {Daily }} / \mathrm{SY}_{\mathrm{Sub}}$ & 1 & $1.05-0.41 \mathrm{RB}$ & 0.33 \\
\hline Suspended Load & $\mathrm{Q}_{\text {s50-Daily }} / \mathrm{Q}_{550-\text {-sub }}$ & 1 & $1.04-0.50 \mathrm{RB}$ & 0.48 \\
\hline Bedload & $\mathrm{SY}_{\text {Daily }} / \mathrm{SY}_{\text {Sub }}$ & 2 & $1.11-0.55 R B-0.03 b$ & 0.51 \\
\hline Bedload & $Q_{s 50-D a i l y} / Q_{s 50-\text { sub }}$ & 2 & $1.12-0.65 R B-0.03 b$ & 0.46 \\
\hline Suspended Load & $\mathrm{SY}_{\text {Daily }} / \mathrm{SY}_{\text {Sub }}$ & 2 & $1.18-0.41 R B-0.07 b$ & 0.37 \\
\hline Suspended Load & $Q_{s 50-D a i l y} / Q_{s 50-S u b}$ & 2 & $1.12-0.50 R B-0.04 b$ & 0.49 \\
\hline Bedload & $S Y_{\text {Daily }} / \mathrm{SY}_{\text {Sub }}$ & $2+$ interaction & $0.95+0.63 R B+0.04 b-0.57 R B * b$ & 0.82 \\
\hline *Bedload & $\mathrm{Q}_{\text {s50-Daily }} / \mathrm{Q}_{550-\text {-sub }}$ & $2+$ interaction & $0.94+0.66 R B+0.05 b-0.63 R B * b$ & 0.72 \\
\hline Suspended Load & $\mathrm{SY}_{\text {Daily }} / \mathrm{SY}_{\text {Sub }}$ & $2+$ interaction & $1.01+0.38 R B+0.02 b-0.43 R B * b$ & 0.46 \\
\hline *Suspended Load & Qs50-Daily / Q & $2+$ interaction & $0.99+0.10 R B+0.03 b-0.32 R B * b$ & 0.53 \\
\hline
\end{tabular}

$\mathrm{RB}=$ Richards-Baker Flashiness index computed with daily-average flow data

$\mathrm{b}=$ Best fit exponent from sediment rating curve

* Used in the development of Figure 11

\section{DISCUSSION}

\subsection{EFFECTIVE DISCHARGE}

The decision to use daily-averaged or sub-daily streamflow data was not found to impact the calculation of effective discharge in a consistent way. Amongst bedload and suspended load sites, the ratio of $Q_{E f f-D a i l y} / Q_{E f f-S u b}$ varied around unity with nearly equal abundance. These results are a byproduct of the sensitivity of the $Q_{E f f}$ calculation to the discretization of the streamflow record as well as the transience of flashy flows, which in some but not all cases 
influence the shape of the flow-frequency distribution when comparing a histogram of flows made from daily average vs. sub-daily flow records.

For ratios of $Q_{E f f-D a i l y} / Q_{E f f-S u b}$ less than unity, differences in the size of the bins (range of discharges) in the discretized flow duration curve histogram were the primary cause for the differences in $Q_{E f f}$. We refer to this as a Type A error. Type A errors were caused by the subdaily flow record nearly always having a larger maximum flow and smaller minimum flow than the daily-averaged flow record. This greater range between the maximum and minimum flow forces the range of flows in each bin to be greater for sub-daily flow data than daily-averaged data, when a fixed number of arithmetically sized bins is used. Because $Q_{E f f}$ was calculated as the median discharge of the bin that produces the maximum sediment yield, $Q_{E f f-S u b}$ was likely to be greater than $Q_{E f f-D a i l y}$ when the same bin was identified as containing $Q_{E f f}$. This type of error is depicted in Figure 7.

Figure 7: Type A error for the Trinity River near Hoopa, CA. Differences in bin sizes cause disparity in QEff, even when the same bin is identified as most effective.

In the case of $Q_{E f f-D a i l y} / Q_{E f f-S u b}$ values that are greater than unity, differences in flow frequency were found to be the primary cause of this type of error, which we termed Type B error. After being multiplied by the sediment rating curve, differences in the frequency of high magnitude discharges between the sub-daily and daily-averaged flow records often caused $Q_{E f f}$ to be located in different bins, thereby causing larger departures in $Q_{E f f}$. At high discharges, these differences in flow frequency could be very small and still cause large differences in $Q_{E f f}$ when the sediment transport rate at that discharge was particularly high. This was a common result for 
flashy $(R B>0.3)$ bedload sites. An example of this type of error is shown in Figure 8, where the arrows in the discharge probability density histograms indicate the effective discharge computed with daily-averaged flows. The sub-daily flow record captures many more high flows and thus produces a smoother histogram and effectiveness curve, which causes the effective discharge bin computed with sub-daily flows to differ dramatically from that computed with daily-averaged flows.

Figure 8: Type B error for the Mad River near Arcata, CA $(R B=0.299)$. Differences in discharge density (indicated by dashed arrows) caused the effective discharge to be located in different bins.

As flashiness increases, the sub-daily flow record departs from the daily-average flow record. This causes Type A and Type B errors to become more prevalent and of greater magnitude. Figure 3 depicts how the departure of $Q_{E f f-D a i l y} / Q_{E f f-S u b}$ from unity can increase with flashiness. These results indicate that $Q_{E f f}$ is very sensitive to the binning method used, the size of individual bins, and slight differences in flow frequency distributions between daily and subdaily flow data. Comparatively, $Q_{s 50}$ does not suffer from the problems associated with representing the flow frequency distribution, and was found to be much more consistent in magnitude than $Q_{E f f}$. However, both $Q_{E f f}$ and $Q_{s 50}$ are sensitive to the slope of the sediment rating curve, $b$, which may be difficult to accurately estimate with sparse sediment transport data, though previous research suggests that $b$ can be accurately estimated for coarse bed sites (Barry et al. 2008). Additionally, recent work suggests that $Q_{s 50}$ may perform better than $Q_{E f f}$ in the 
prediction of bankfull discharge for fine bed streams (Sholtes and Bledsoe, 2016). Therefore, for certain applications such as channel design, $Q_{s 50}$ may be a more useful metric than $Q_{E f f}$.

\subsection{ESTIMATING ERROR IN SEDIMENT YIELD AND HALF-LOAD DISCHARGE CALCULATIONS}

Using the 2-variable interaction model developed through multi-variate linear regression (Table 1), we can quantitatively describe the differences in $S Y$ and $Q_{s 50}$ values resulting from daily-averaged versus sub-daily flow data. Figures 9 and 10 present the percent disagreement between sub-daily and daily values of $S Y$ and $Q_{s 50}$ as a function of $R B$ and $b$.

Figure 9: Percent difference in sediment yield ( $S Y$ ) (values labeled at the top of contours) calculated with daily-averaged flow data. a) bedload sites b) suspended load sites

Figure 10: Percent difference in half-load discharge $\left(Q_{s 50}\right)$ (values labeled at the top of contours) calculated with daily-averaged flow data. a) bedload sites b) suspended load sites.

Because estimating disagreement in $S Y$ and $Q_{s 50}$ computed with daily-averaged flow data using Figures 9 and 10 requires $b$, it is important to have a reliable method for estimating $b$. The logarithmic slope of the sediment transport function, $b$, is thought to represent a number of physical watershed characteristics including basin area, the erosive power of the river, and the extent to which new sediment sources become available as discharge increases (Asselman, 2000; Syvitski et al., 2000; Bunte et al., 2015). The parameter $b$ can be most reliably estimated by using a series of sediment discharge measurements and corresponding flow rates to fit a power 
law function to these data; however, these measurements are often not available and it can be cost-prohibitive to collect new sediment discharge measurements. In this case, one may use channel geometry and slope measurements with a total bed material load equation (e.g., Bagnold, 1966; Einstein, 1950; Yang, 1973; Brownlie, 1981) to estimate sediment transport as a function of discharge, from which $b$ can be determined. If local channel geometry data are also unavailable, one may have to rely on a regression equation in order to estimate $b$. In this circumstance, regression equations developed for localized conditions are generally best, but when these are not available, more global regression equations may be carefully considered (Syvitski et al., 1999; Bunte and Abt, 2003).

\subsection{IMPLICATIONS FOR DESIGN OF CHANNEL BED SLOPE}

Sediment yield calculations for flashy systems $(R B>0.4)$ with a moderate to large sediment rating curve exponent $(b>2)$ using daily-averaged flow data are at risk of greatly underestimating sediment yield. To quantify the potential effect of underestimating sediment yield on channel design, we use a stable channel proportionality (Henderson, 1966) as a first approximation to explore how channel design slope may differ when using daily-averaged or sub-daily flow data. Henderson (1966) combined the Einstein sediment transport function as revised by Brown (1950), the Chezy flow resistance formula, and momentum and mass conservation for steady uniform flow into a single proportionality where $q_{s}$ is the unit sediment transport rate, $q$ is the unit water discharge, $S$ is the channel slope, and $D$ is the grain size:

$$
q_{s} \propto \frac{q^{2} S^{2}}{D^{\frac{3}{2}}}
$$

Rearranging for channel slope yields: 


$$
S \propto \sqrt{\frac{D^{\frac{3}{2}} q_{s}}{q^{2}}}
$$

Comparing a slope resulting from daily-averaged discharges to one resulting from sub-daily discharges yields:

$$
\frac{S_{\text {Daily }}}{S_{\text {Sub }}} \propto \frac{\sqrt{\frac{D^{\frac{3}{2}} q_{\text {s-Daily }}}{q_{\text {Daily }}^{2}}}}{\sqrt{\frac{D^{\frac{3}{2}} q_{\text {S-Sub }}}{q_{\text {Sub }}^{2}}}}
$$

Wilcock (2004) suggested that the generic form of the relationship in Equation 4 could be used to check for the potential aggradation or degradation of a channel. A ratio of $\frac{S_{\text {Daily }}}{S_{S u b}}$ that is less than unity suggests that use of daily-averaged flow data may result in a bed slope $\left(S_{\text {Daily }}\right)$ that is too low, thus creating potential for channel aggradation. Likewise, if the ratio of $\frac{S_{\text {Daily }}}{S_{S u b}}$ is greater than unity, $S_{\text {Daily }}$ may be overestimated, creating potential for channel degradation.

For our purposes, we assume that bed sediment size remains constant and simplify Equation 4, yielding:

$$
\frac{S_{\text {Daily }}}{S_{\text {Sub }}} \propto \sqrt{\frac{q_{s-\text { Daily }}}{q_{s-S u b}}} *\left(\frac{q_{\text {Daily }}}{q_{\text {Sub }}}\right)^{-1}
$$

Replacing $q_{s}$ with a sediment rating curve $\left(q_{s}=a q^{b}\right)$ yields:

$$
\frac{S_{\text {Daily }}}{S_{\text {Sub }}} \propto \sqrt{\frac{a q_{\text {Daily }}^{b}}{a q_{\text {Sub }}^{b}}}\left(\frac{q_{\text {Daily }}}{q_{\text {Sub }}}\right)^{-1}=\left(\frac{q_{\text {Daily }}}{q_{\text {Sub }}}\right)^{\frac{b}{2}-1}
$$

Evaluation of (6) requires an estimate of a single dominant discharge, computed with dailyaveraged and sub-daily flow data. Sholtes and Bledsoe (2016) have shown that $Q_{s 50}$ is a useful 
process-based predictor of bankfull discharge, so if we use $Q_{s 50}$ as our measure of discharge, we arrive at:

$$
\frac{S_{\text {Daily }}}{S_{\text {Sub }}} \propto\left(\frac{Q_{s 50-\text { Daily }}}{Q_{S 50-S u b}}\right)^{\frac{b}{2}-1}
$$

The ratio of $Q_{s 50-D a i l y} / Q_{s 50--S u b}$ in Equation (7) can be estimated for both bedload and suspended load sites using the two variable plus interaction relationships presented in Table 1 (denoted with an asterisk in column 1). We can then use Equation (7) to plot the amount by which a design slope calculated using daily-average flow data, $S_{\text {Daily }}$, differs from the design slope calculated with sub-daily flow data, $S_{S u b}$. Presumably the slope calculated such that sediment continuity is achieved based on sediment yield estimates made from sub-daily flow data $\left(S_{S u b}\right)$ should be closer to a true equilibrium slope (that is, more accurate). Figure 11 shows that for both bedload and suspended load sites, high flashiness and high $b$ values correspond to low values of $\frac{S_{\text {Daily }}}{S_{S u b}}$. This indicates that using daily-averaged flow data in these types of conditions would result in a channel design slope that is greatly underestimated, which could lead to channel aggradation. Conversely, for both suspended load and bedload sites there exist certain combinations of flashiness and $b$ that cause $\frac{S_{\text {Daily }}}{S_{S u b}}$ to exceed 1 . These are areas with a $R B$ flashiness less than 0.1 and a $b$ greater than 4 , an unlikely combination. For suspended load sites, these are also areas with a $R B$ flashiness greater than 0.8 and $b$ near 1 , also unlikely. In these cases, daily-averaged flow data causes an over-estimation of channel design slope, which could potentially cause channel degradation. 
Figure 11: Ratio of design slope calculated with daily flow data $\left(S_{\text {Daily }}\right)$ to the design slope calculated with sub-daily flow data $\left(S_{S u b}\right)$ : a) bedload sites b) suspended load sites

\section{CONCLUSIONS}

Our analysis of the effects of flow data resolution on sediment transport calculations for 39 bed load sites and 99 suspended load sites suggests that the use of daily-averaged flow data is not always appropriate because it can result in a substantial underestimation of sediment yield metrics if stream flashiness or the exponent of the sediment rating curve are high $(R B>0.4$ or $b$ >2). The effect of flow data resolution on the computation of effective discharge, $Q_{E f f}$, was not readily predictable as a function of stream flashiness index, $R B$, or sediment rating curve exponent, $b$, because $Q_{E f f}$ is highly sensitive to the procedure used represent the flow frequency distribution. Deviations of values of the half-load discharge, $Q_{s 50}$, and the sediment yield, $S Y$, calculated with daily vs. sub-daily streamflow data correlate well with stream flashiness $R B$ and the rating curve exponent $b$. This is understandable from a theoretical standpoint, as sediment transporting flows are more likely to be missed or underestimated by daily average flow data when a stream is flashy, and the impact of the error is greater when the sediment rating curve is steep. In instances where the flow regime at a site is flashy $(R B>0.4)$ and the sediment rating curve exponent is greater than two $(b>2), S Y$ and $Q_{s 50}$ were greatly underestimated using dailyaveraged flow data. This underestimation of $S Y$ and $Q_{s 50}$ may then lead to underestimation of channel design slope, which could ultimately cause channel aggradation (Figure 11).

Additionally, even in instances where flashiness was high, low logarithmic sediment rating curve slope ( $b \approx 1$ ) controlled the magnitude of error in sediment yield and $Q_{s 50}$ calculations, causing 
error to be quite small. Based on these results, it is better to use sub-daily discharge data for sediment transport calculations when the site either has a $R B$ flashiness greater than 0.4 or $b$ is greater than 2. This should help keep the error of sediment transport metrics $\left(S Y, Q_{s 50}\right)$ and channel design slope computed with daily-averaged flow data to within $20 \%$ when compared to the same metrics computed with sub-daily flow data.

\section{NOTATION}

$a=$ sediment rating curve best fit coefficient

$b=$ sediment rating curve best fit exponent, logarithmic slope of sediment transport

$D_{50}=$ median grain size $(\mathrm{mm})$

$D_{84}=84^{\text {th }}$ percentile grain size $(\mathrm{mm})$

$p=$ probability of rejecting the null hypothesis when the null hypothesis is true

$Q_{E f f}=$ effective discharge $\left(\frac{m^{3}}{s}\right)$

$Q_{E f f-D a i l y}=$ effective discharge computed with daily-averaged flow data $\left(\frac{\mathrm{m}^{3}}{\mathrm{~s}}\right)$

$Q_{E f f-S u b}=$ effective discharge computed with sub-daily flow data $\left(\frac{\mathrm{m}^{3}}{\mathrm{~s}}\right)$

$Q_{s 50}=$ discharge below which $50 \%$ of bed material load is transported $\left(\frac{m^{3}}{\mathrm{~s}}\right)$

$Q_{s 50-\text { Daily }}=$ discharge below which $50 \%$ of sediment is transported, computed from daily flow data $\left(\frac{m^{3}}{s}\right)$

$Q_{s 50-S u b}=$ discharge below which $50 \%$ of sediment is transported, computed from sub-daily flow data $\left(\frac{m^{3}}{s}\right)$

$R B=$ Richards-Baker Flashiness Index (Baker et al., 2004)

$S_{\text {Daily }}=$ Design slope computed from daily flow data

$S_{S u b}=$ Design slope computed from sub-daily flow data

$S Y=$ Sediment yield $\left(\mathrm{m}^{3}\right)$

$S Y_{\text {Daily }}=$ Sediment yield computed with daily flow data $\left(\mathrm{m}^{3}\right)$

$S Y_{\text {Sub }}=$ Sediment yield computed with sub-daily flow data $\left(\mathrm{m}^{3}\right)$ 


\section{ACKNOWLEDGMENTS}

This research was financially supported by National Cooperative Highway Research Program Project 24-40. J. Sholtes was also supported by the National Science Foundation IGERT Grant No. DGE-0966346 “I-WATER: Integrated Water, Atmosphere, Ecosystems Education and Research program" at Colorado State University. Constructive reviews from two anonymous reviewers improved the clarity of the manuscript. 


\section{REFERENCES}

Ågren, A., Buffam, I., Jansson, M., Laudon, H. (2007). Importance of seasonality and small streams for the landscape regulation of dissolved organic carbon export. Journal of Geophysical Research: Biogeosciences, 112(3). DOI: 10.1029/2006JG000381.

Allan, J. D., Castillo, M. M. (2007). Stream Ecology: Structure and Function of Running Waters. Springer Science \& Business Media. ISBN: 978-1-4020-5582-9.

Andrews, E. D. (1980). Effective and bankfull discharges of streams in the Yampa River basin, Colorado and Wyoming. Journal of Hydrology, 46(3), 311-330. DOI: 10.1016/00221694(80)90084-0.

Andrews, E. D. (1994), Marginal bed load transport in a gravel bed stream, Sagehen Creek, California, Water Resources Research, 30(7), 2241-2250. DOI: 10.1029/94WR00553.

Asselman, N. E. M. (2000). Fitting and interpretation of sediment rating curves. Journal of Hydrology, 234(3), 228-248. DOI: 10.1016/S0022-1694(00)00253-5.

Bagnold, R.A. (1966). An approach to the sediment transport problem from general physics. Professional Paper 422-I. U.S. Geological Survey, Washington, D.C.

Baker, D. B., Richards, R. P., Loftus, T. T., Kramer, J. W. (2004). A new flashiness index: characteristics and applications to Midwestern rivers and streams. Journal of the American Water Resources Association, 40(2), 503-522. DOI: 10.1111/j.17521688.2004.tb01046.x

Barry, J. J., Buffington, J. M., King, J. G. (2004). A general power equation for predicting bed load transport rates in gravel bed rivers. Water Resources Research, 40(10). DOI:10.1029/2004WR003190. 
Barry, J. J., Buffington, J. M., Goodwin, P., King, J. G., Emmett, W. W. (2008). Performance of bed-load transport equations relative to geomorphic significance: predicting effective discharge and its transport rate. Journal of Hydraulic Engineering, 134(5), 601-615. DOI: 10.1061/(ASCE)0733-9429(2008)134:5(601).

Biedenharn, D. S., Copeland, R. R., Thorne, C. R., Soar, P. J., Hey, R. D., Watson, C. C. 2000. "Effective discharge calculation: A practical guide.” Technical Rep. No. ERDC/CHL TR-00-15, U.S. Army Corps of Engineers, Washington, D.C.

Borcher, H.W. (2015). Pracma: Practical Numerical Math Functions. R package version 1.8.8. https://cran.r-project.org/web/packages/pracma/index.html.

Brown, C. B. (1950). Sediment transportation. In Engineering hydraulics, ed. H. Rouse. New York: Wiley. pp. 769-857.

Brownlie, W.R. (1981). Prediction of flow depth and sediment discharge in open-channels. Report no. KH-R-43A. Pasadena: California Institute of Technology, W.M. Keck Laboratory.

Bunte, K., Abt, S.R. (2003). "Bedload rating and flow competence curves vary with watershed and bed material parameters," EOS, Trans. AGU, 84 (46) Fall Meeting Supplement, Abstract H32I-01.

Bunte, K., Abt, S.R., Swingle, K.W, Cenderelli, D.A., Rickenmann, D., Gaeuman, D. (2015). Scaling relations for exponents and coefficients of bedload transport and flow competence curves in coarse-bedded streams with channel gradient, runoff yield, basin area, and subsurface fines. Paper presented at the $3^{\text {rd }}$ Joint Federal Interagency 
Conference on Sedimentation and Hydrologic Modeling, Reno, Nevada, USA. Retrieved from http://www. http://acwi.gov/sos/pubs/3rdJFIC/Proceedings.pdf.

Cade, B. S., Noon, B. R. (2003). A gentle introduction to quantile regression for ecologists. Frontiers in Ecology and the Environment, 1(8), 412-420. DOI: http://dx.doi.org/10.1890/1540-9295(2003)001[0412:AGITQR]2.0.CO;2.

Colby, B. R. (1956). Relationship of sediment discharge to streamflow. Open File Rep., U.S. Geological Survey, Water Resources Division, Washington, D.C.

Curran, J. C., Waters, K. A., Cannatelli, K. M. (2015). Real time measurements of sediment transport and bed morphology during channel altering flow and sediment transport events. Geomorphology, 244, 169-179. DOI: 10.1016/j.geomorph.2015.03.009.

Doyle, M. W., Shields, D., Boyd, K. F., Skidmore, P. B., Dominick, D. (2007). Channel-forming discharge selection in river restoration design. Journal of Hydraulic Engineering, 133(7), 831-837. DOI: 10.1061/(ASCE)0733-9429(2007)133:7(831).

Dubler, D. (1997). Effective Discharge Determination in the Yazoo River Basin, Mississippi. Masters Thesis, Colorado State University, Department of Civil and Environmental Engineering, Fort Collins, CO.

Einstein, H.A. (1950). The bed load function for sediment transport in open channel flows. Technical Bulletin no. 1026. Washington, D.C.: U.S. Department of Agriculture, Soil Conservation Service.

Emmett, W. W., Wolman, M. G. (2001). Effective discharge and gravel-bed rivers. Earth Surface Processes and Landforms, 26(13), 1369-1380. DOI: 10.1002/esp.303.

Ferguson, R. I. (1987). Accuracy and precision of methods for estimating river loads. Earth surface processes and landforms, 12(1), 95-104. DOI: 10.1002/esp.3290120111. 
Graf, W. L. (1977). Network characteristics in suburbanizing streams. Water Resources Research, 13(2), 459-463. DOI: 10.1029/WR013i002p00459.

Henderson, F. M. (1966). Open channel flow. Macmillan.

Hendon, S. (1995). Comparison of 15-Minute Versus Mean Daily Flow Duration Curves From The Yazoo Basin, MS. Masters Thesis, Colorado State University, Department of Civil and Environmental Engineering, Fort Collins, CO.

Koenker, R., Bassett Jr, G. (1978). Regression quantiles. Econometrica: Journal of the Econometric Society, 46, 33-50.

Konrad, C. P., Booth, D. B. (2002). Hydrologic trends associated with urban development for selected streams in the Puget Sound Basin, western Washington. United States Geological Survey Water-Resources Investigations Report 02-4040, Tacoma, Washington.

Kuhnle, R. A., Southard, J. B. (1988). Bed load transport fluctuations in a gravel bed laboratory channel. Water Resources Research, 24, 247-260. DOI: 10.1029/WR024i002p00247.

Lumley, T., Miller, A. (2009). Leaps: regression subset selection. R package version 2.9. http://C RAN.R-project.org/package=leaps

Moog, D.B., \& Whiting, P.J. (1998). Annual hysteresis in bed load rating curves. Water Resources Research, 34(9), 2393-2399. DOI: 10.1029/98WR01658.

PRISM Climate Group, Oregon State University, http://prism.oregonstate.edu, created 1 Jan 2015.

R Core Team (2014), R: A Language and Environment for Statistical Computing, R Foundation for Statistical Computing. Vienna, Austria. 
Shields, F. D., Copeland, R. R., Klingeman, P. C., Doyle, M. W., Simon, A. (2003). Design for stream restoration. Journal of Hydraulic Engineering, 129(8), 575-584. DOI: 10.1061/(ASCE)0733-9429(2003)129:8(575).

Sholtes, J.S. (2015). On the magnitude and frequency of sediment transport in rivers. Doctoral dissertation. Colorado State University, Department of Civil and Environmental Engineering, Fort Collins, CO.

Sholtes, J.S., Bledsoe, B.P. (2016). Half-yield discharge: Process-based predictor of bankfull discharge. Journal of Hydraulic Engineering, 04016017. DOI:

10.1061/(ASCE)HY.1943-7900.0001137.

Soar, P. J., Thorne, C. R. (2001). Channel restoration design for meandering rivers. Rep. No. ERDC/CHL CR-01-1, U.S. Army Engineer Research and Development Center, Vicksburg, Miss.

Soar, P. J., Thorne, C. R. (2013). Design discharge for river restoration. Stream Restoration in Dynamic Fluvial Systems, 123-149. DOI: 10.1029/2010GM001009

Syvitski, J. P., Morehead, M. D. (1999). Estimating river-sediment discharge to the ocean: application to the Eel margin, northern California. Marine Geology, 154(1), 13-28. DOI: 10.1016/S0025-3227(98)00100-5.

Syvitski, J. P., Morehead, M. D., Bahr, D. B., Mulder, T. (2000). Estimating fluvial sediment transport: the rating parameters. Water Resources Research, 36(9), 2747-2760.

USFS. (2014), Sediment Transport in Colorado and Wyoming, <http://www.fs.fed.us/rm/boise/AWAE/projects/sediment transport/sediment transport COWY.html>. Accessed May 18, 2014. 
USFS. Boise Adjudication Team (2014), Sediment Transport in Idaho and Nevada, <http://www.fs.fed.us/rm/boise/AWAE/projects/sediment_transport/sediment_transport_B AT.shtml>. Accessed May 18, 2014.

USGS. Center for Integrated Data Analytics (2014), USGS Sediment Data Portal, http://cida.usgs.gov/sediment/. Accessed May 18, 2014.

USGS (2014), National Water Information System, <http://waterdata.usgs.gov/nwis/>

Venables, W. N., Ripley, B. D. (2002) Modern Applied Statistics with S. Fourth Edition. Springer, New York. ISBN 0-387-95457-0.

Walling, D. E. (1977). Limitations of the rating curve technique for estimating suspended sediment loads, with particular reference to British rivers. Erosion and solid matter transport in inland waters, IAHS Publ. 122:34-48.

Walsh, C. J., Roy, A. H., Feminella, J. W., Cottingham, P. D., Groffman, P. M., Morgan, R. P. (2005). The urban stream syndrome: current knowledge and the search for a cure. Journal of the North American Benthological Society, 24(3), 706-723. DOI: http://dx.doi.org/10.1899/04-028.1.

Wang, J., Zamar, R., Marazzi, A., Yohai, V., Salibian-Barrera, M., Maronna, R., Zivot, E., Rock e, D., Martin, D., Maechler, M., Konis, K. (2014). Robust. R package version 0.4-16. http s://cran.r-project.org/web/packages/robust/index.html

Wilcock, P.R. (2004). Sediment transport in the restoration of gravel-bed rivers. ASCE Conference Proceedings, 138: 433. DOI: 10.1061/40737(2004)433.

Wolman, M. G., Miller, J. (1960). Magnitude and frequency of forces of geomorphic processes. Journal of Geology, 68, 54-74. Retrieved from http://www.jstor.org/stable/30058255. 
Yang, C. T. (1973). Incipient motion and sediment transport. Journal of the Hydraulics Division, 99(10), 1679-1704. 


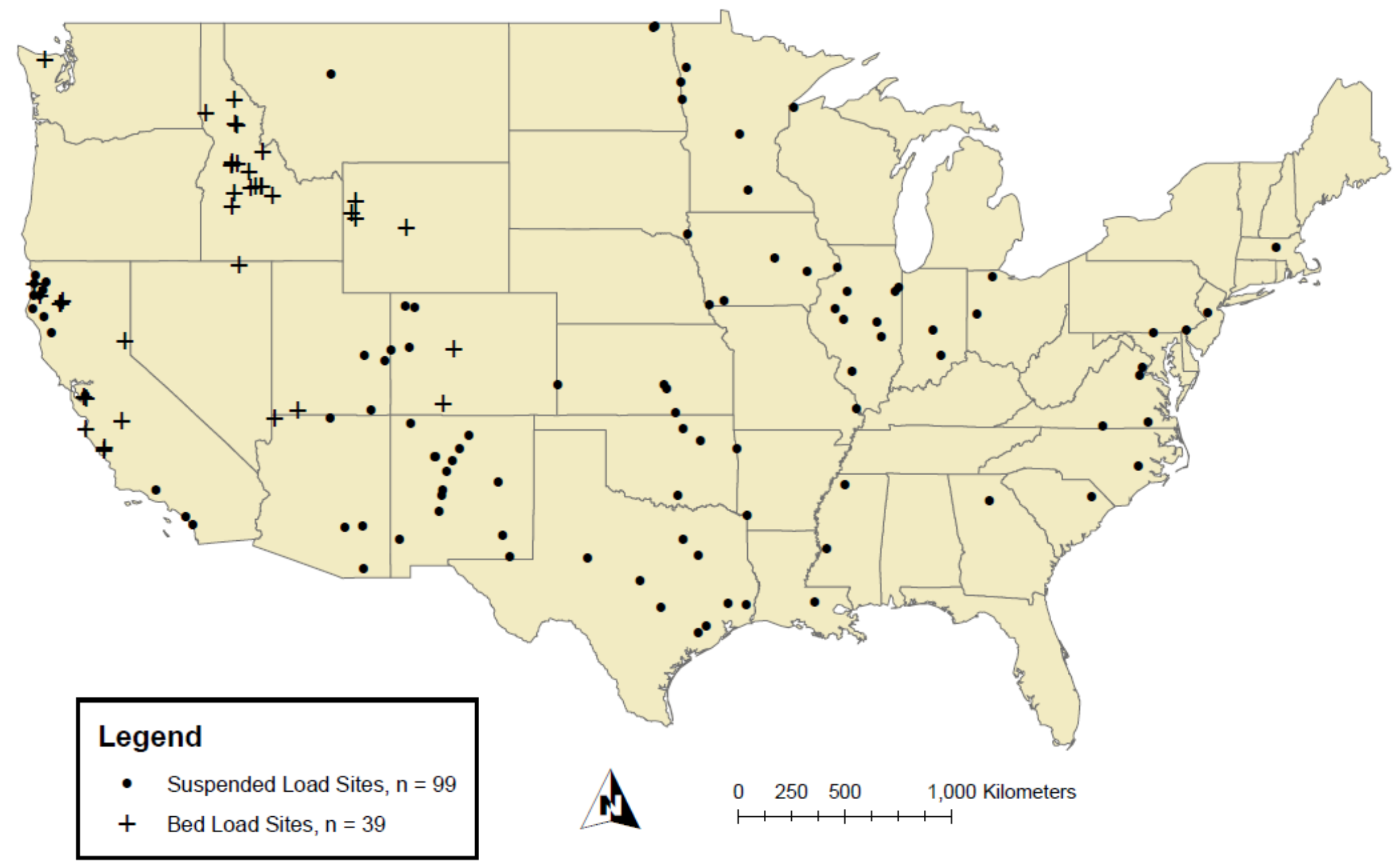

Figure 1: Map of sites used in this study 


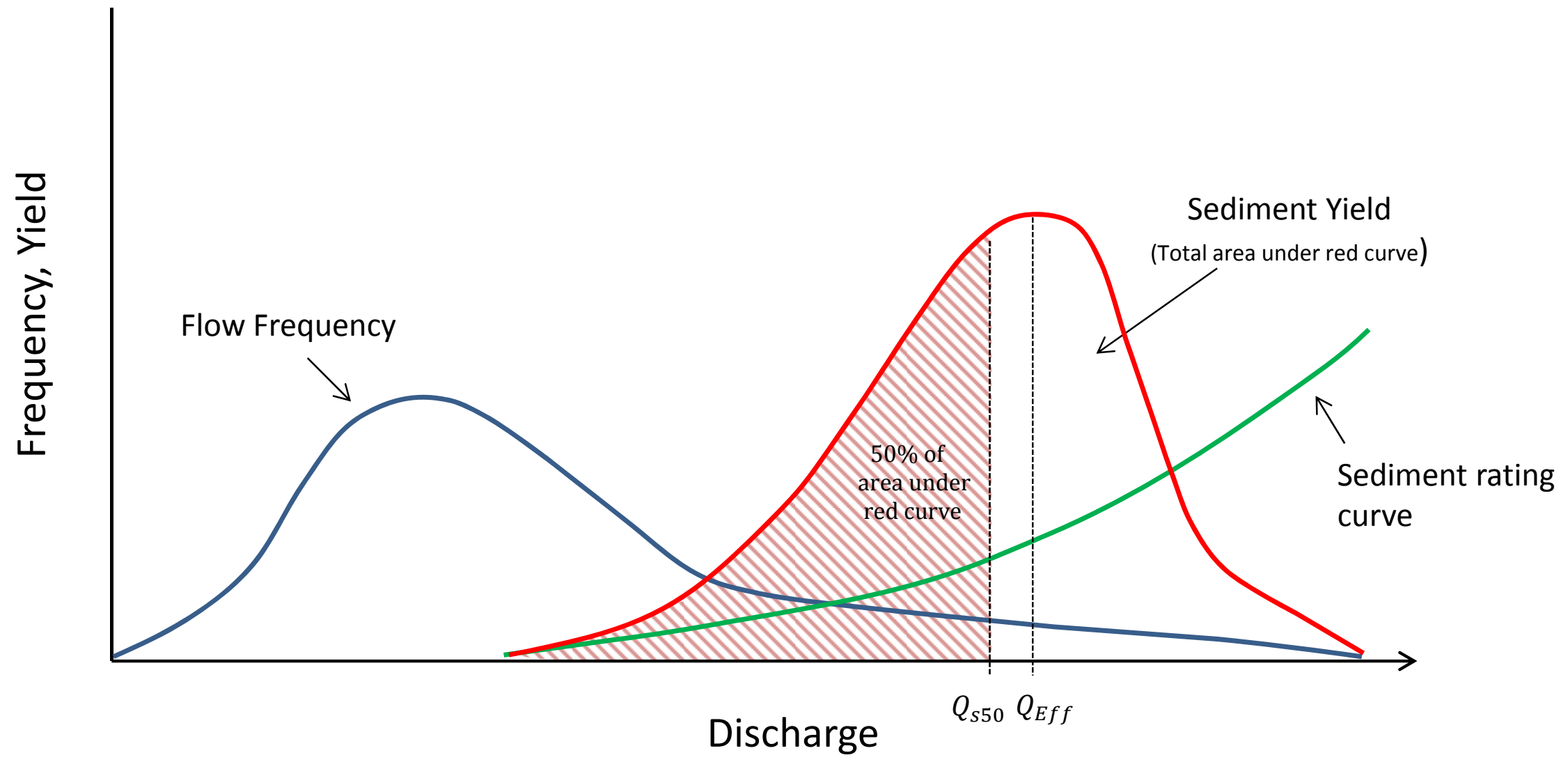

Figure 2: Qualitative illustration of sediment transport metrics used in this study 


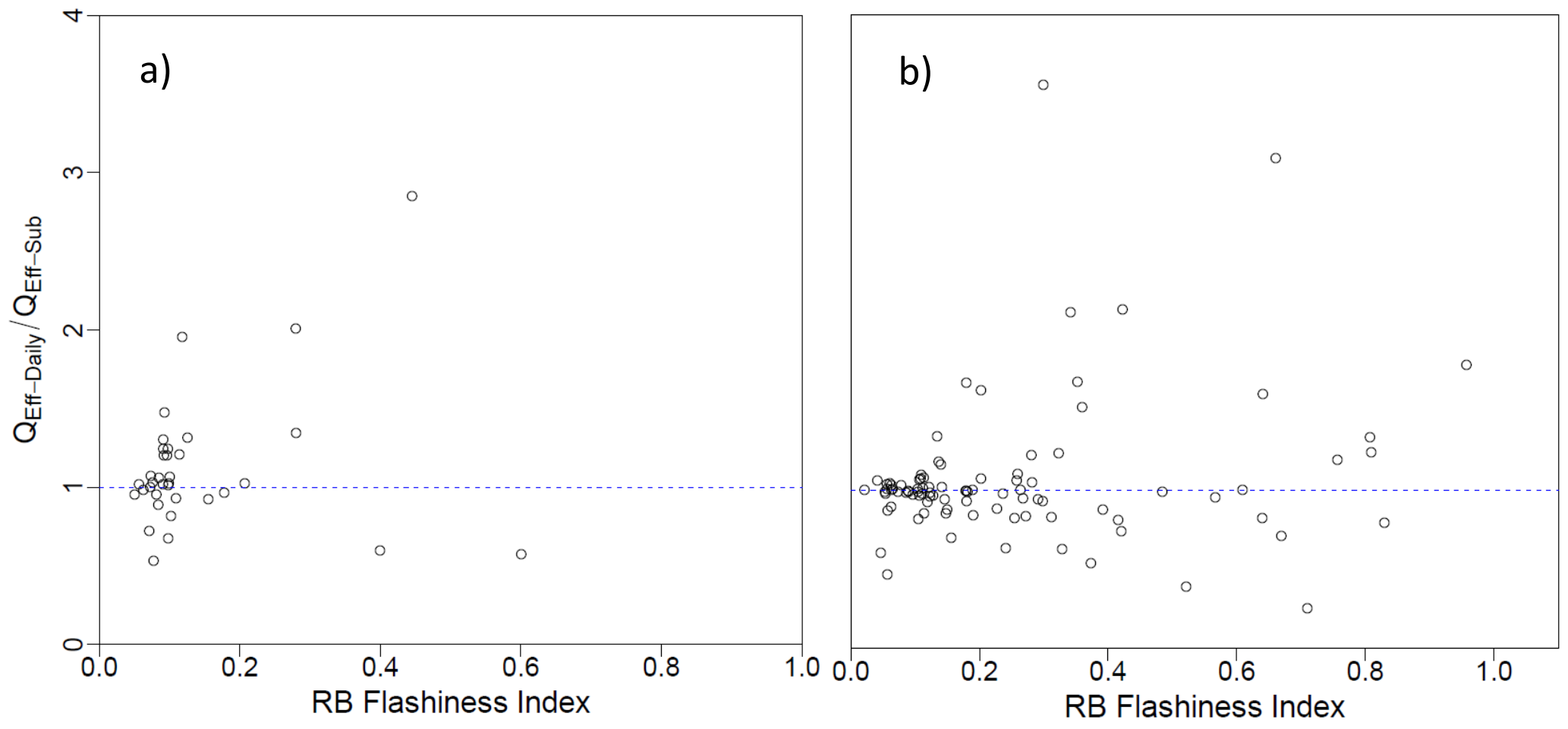

Figure 3: Ratio of effective discharge computed with daily-averaged flow to sub-daily flow vs. the RichardsBaker flashiness index: a) bedload sites b) suspended load sites. 


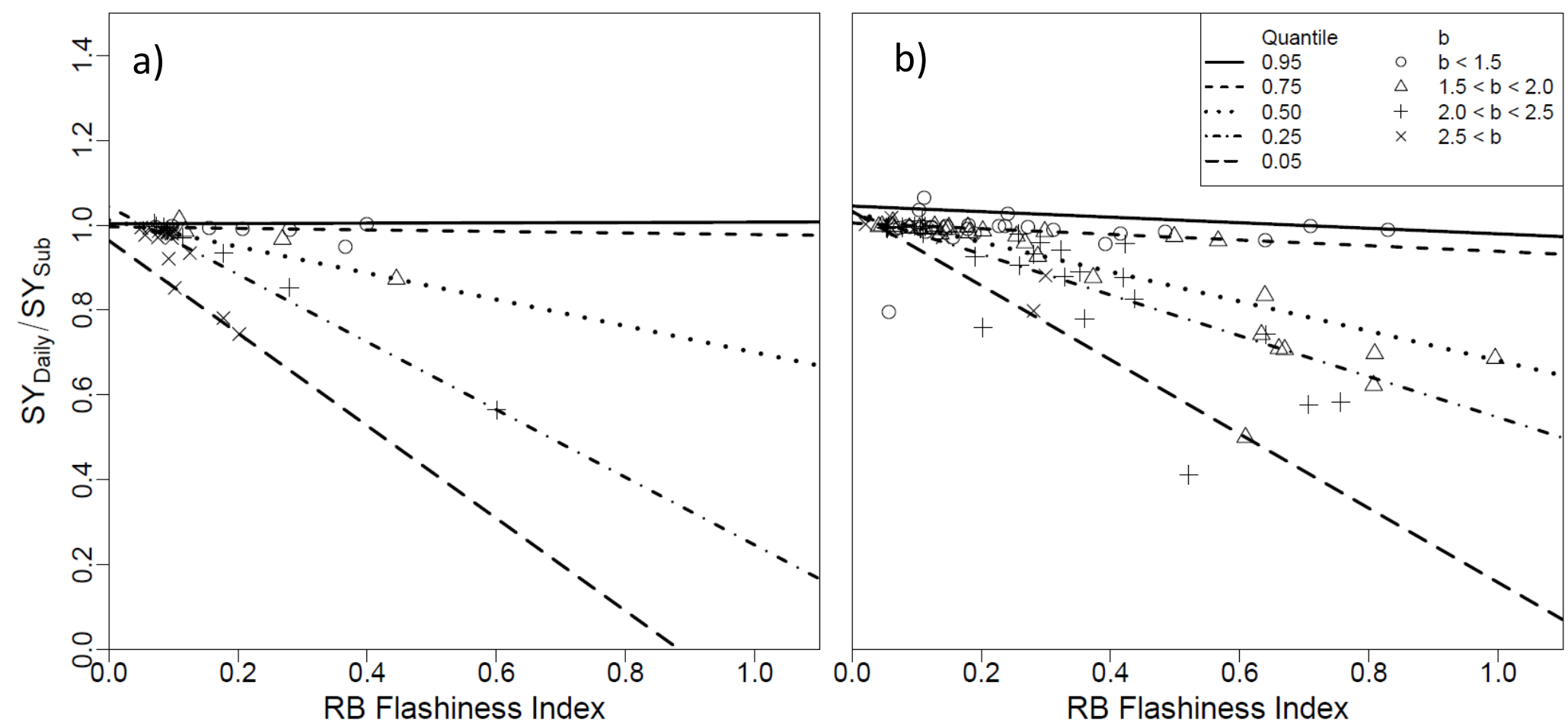

Figure 4:Ratio of sediment yield computed with daily-averaged flow to sub-daily flow vs. the Richards-Baker flashiness index: a) bedload sites b) suspended load sites. Data points categorized by $b$ (sediment rating curve exponent). 


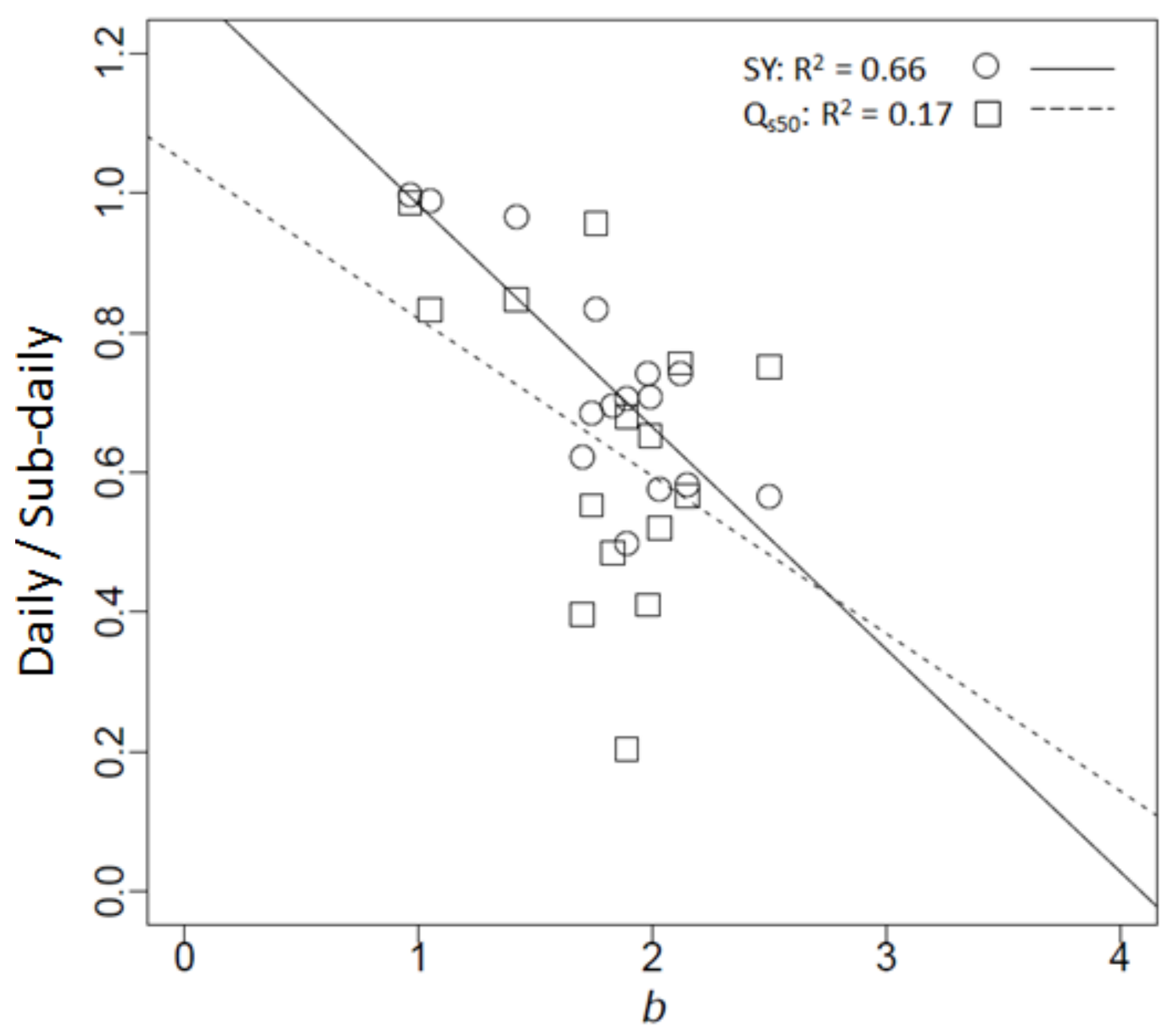

Figure 5: Relationship between the underestimation of $S Y, Q_{s 50}$, and the sediment rating curve best fit exponent, $b$, for suspended load sites with a $R B$ flashiness greater than 0.6. 

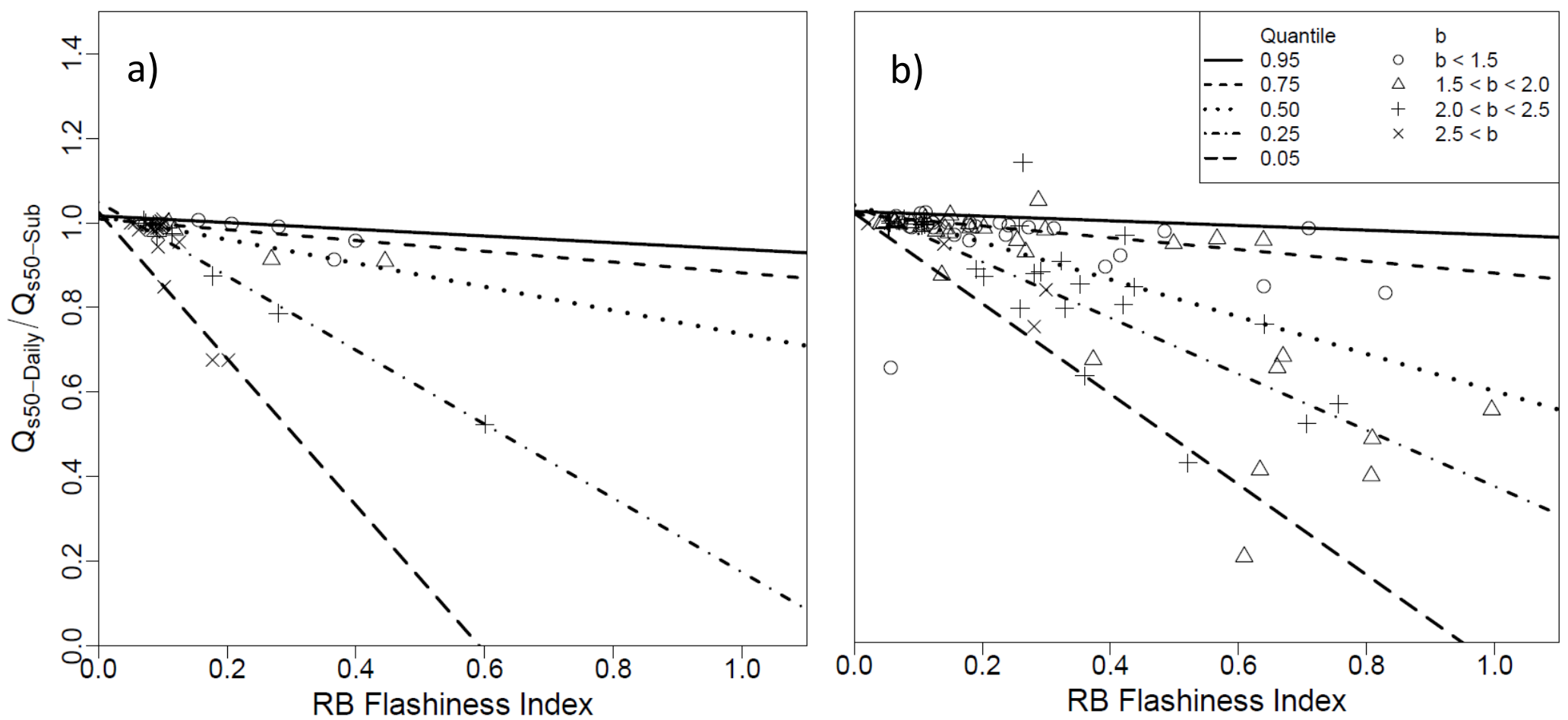

Figure 6: Ratio of discharge below which $50 \%$ of sediment is transported computed with daily-averaged flow to sub-daily flow vs. the Richards-Baker flashiness index: a) bedload sites b) suspended load sites. Data points categorized by $b$ (sediment rating curve exponent). 


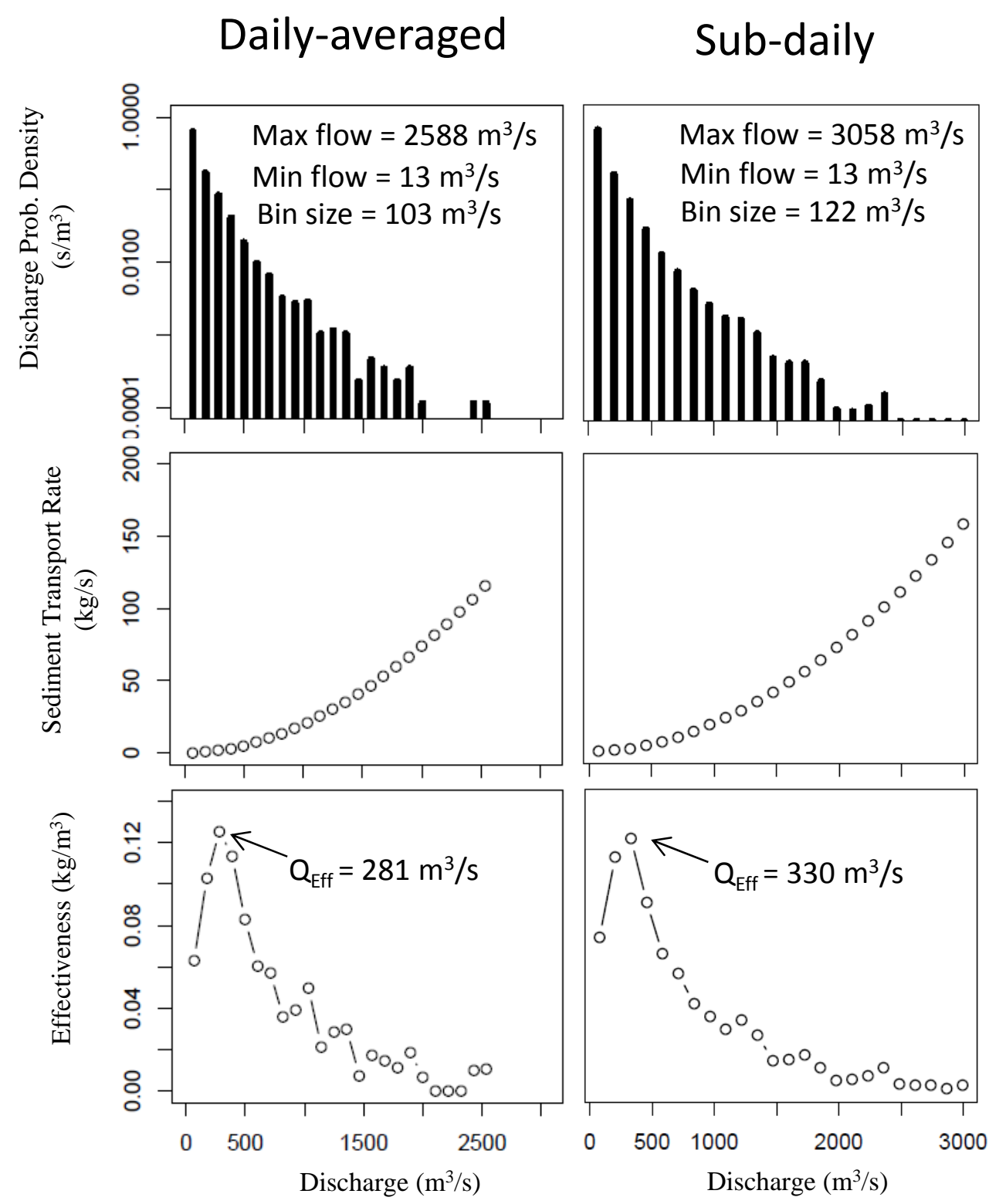

Figure 7: Type A error for the Trinity River near Hoopa, CA. Differences in bin sizes cause disparity in $\mathrm{Q}_{\mathrm{Eff}}$, even when the same bin is identified as most effective. 

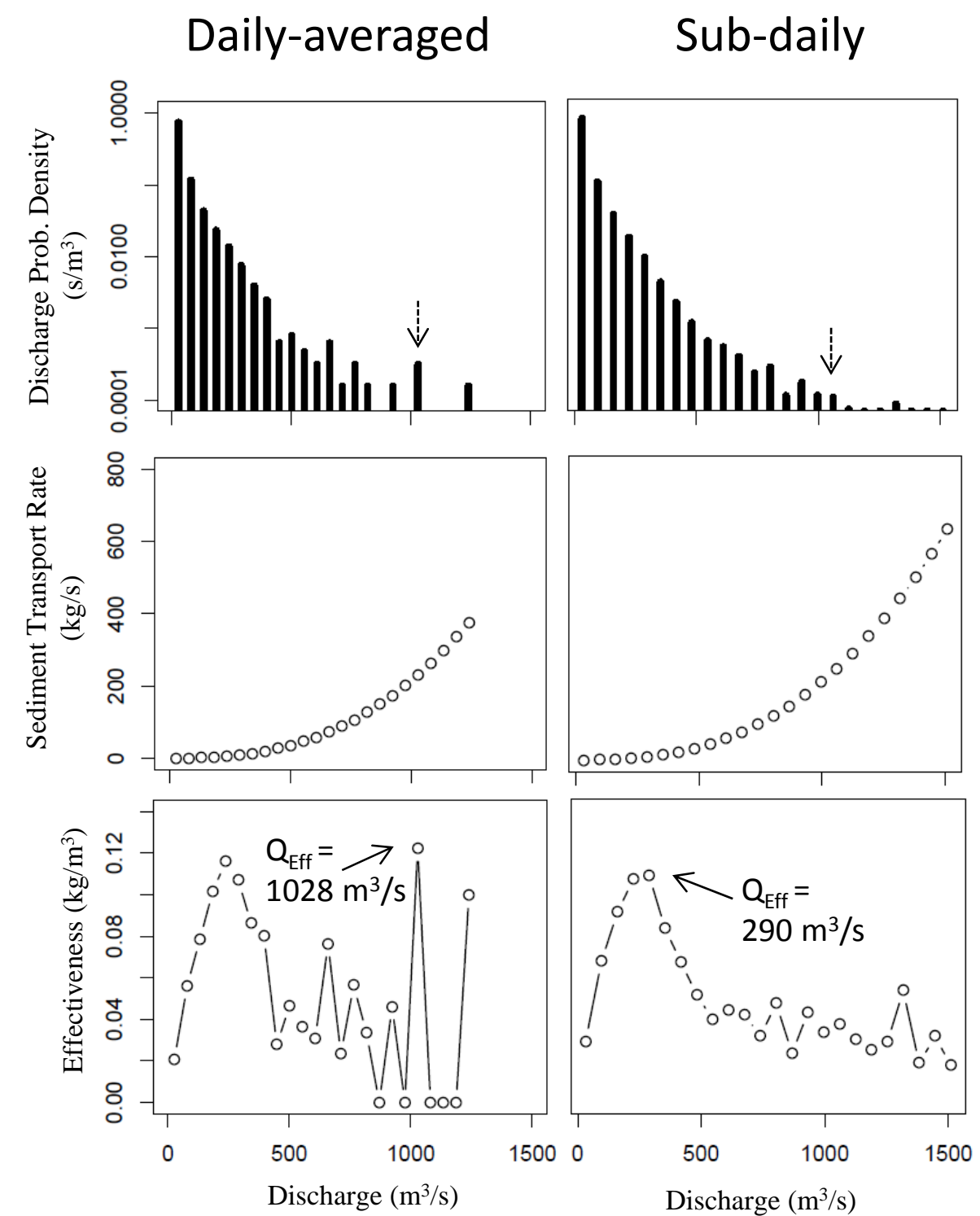

Figure 8: Type B error for the Mad River near Arcata, CA $(R B=0.299)$. Differences in discharge probability density (indicated by dashed arrows) caused the effective discharge to be located in different bins. 

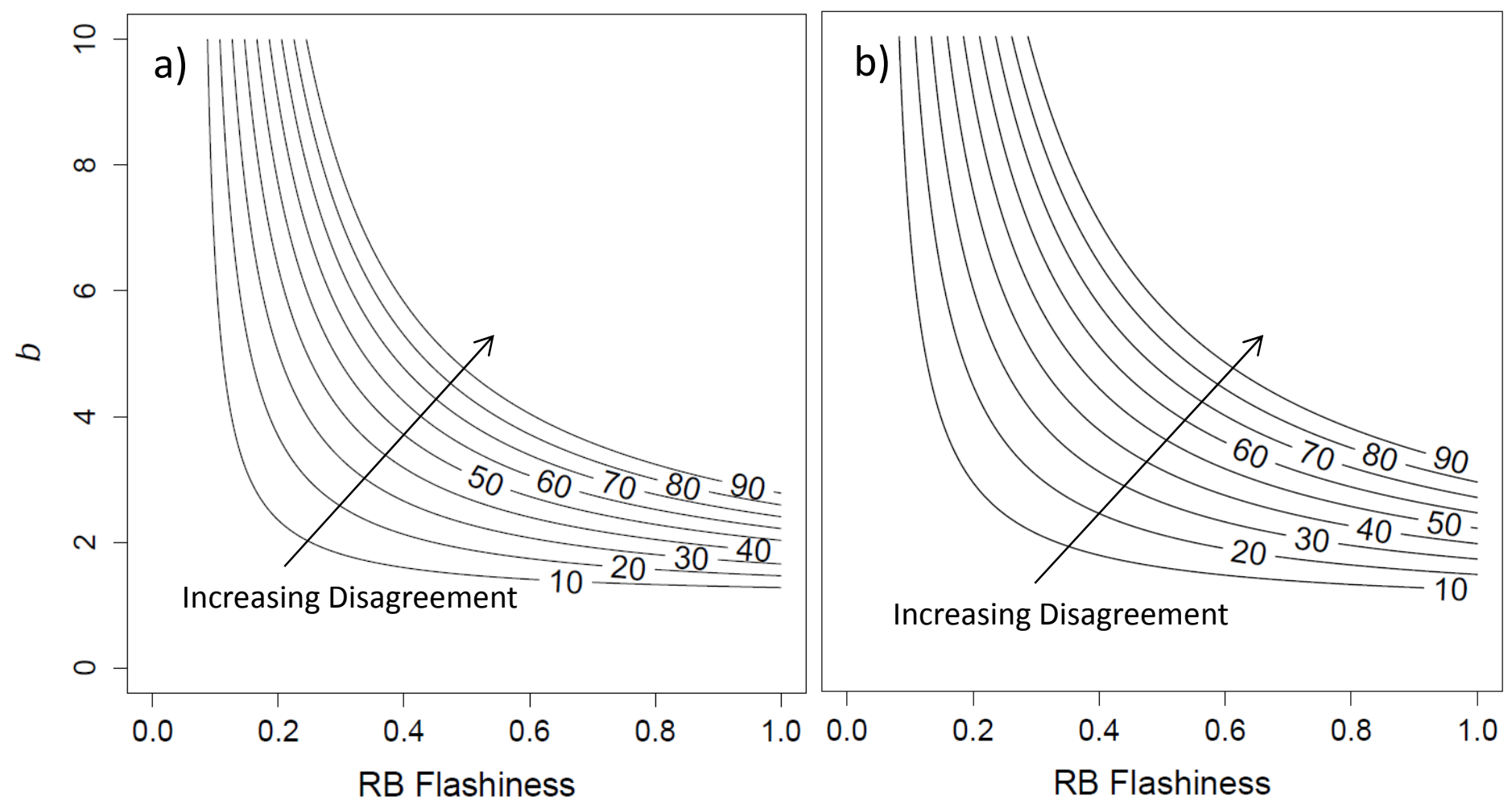

Figure 9: Percent difference in sediment yield (SY) (values labeled at the top of contours) calculated with daily-averaged flow data. a) bedload sites b) suspended load sites 

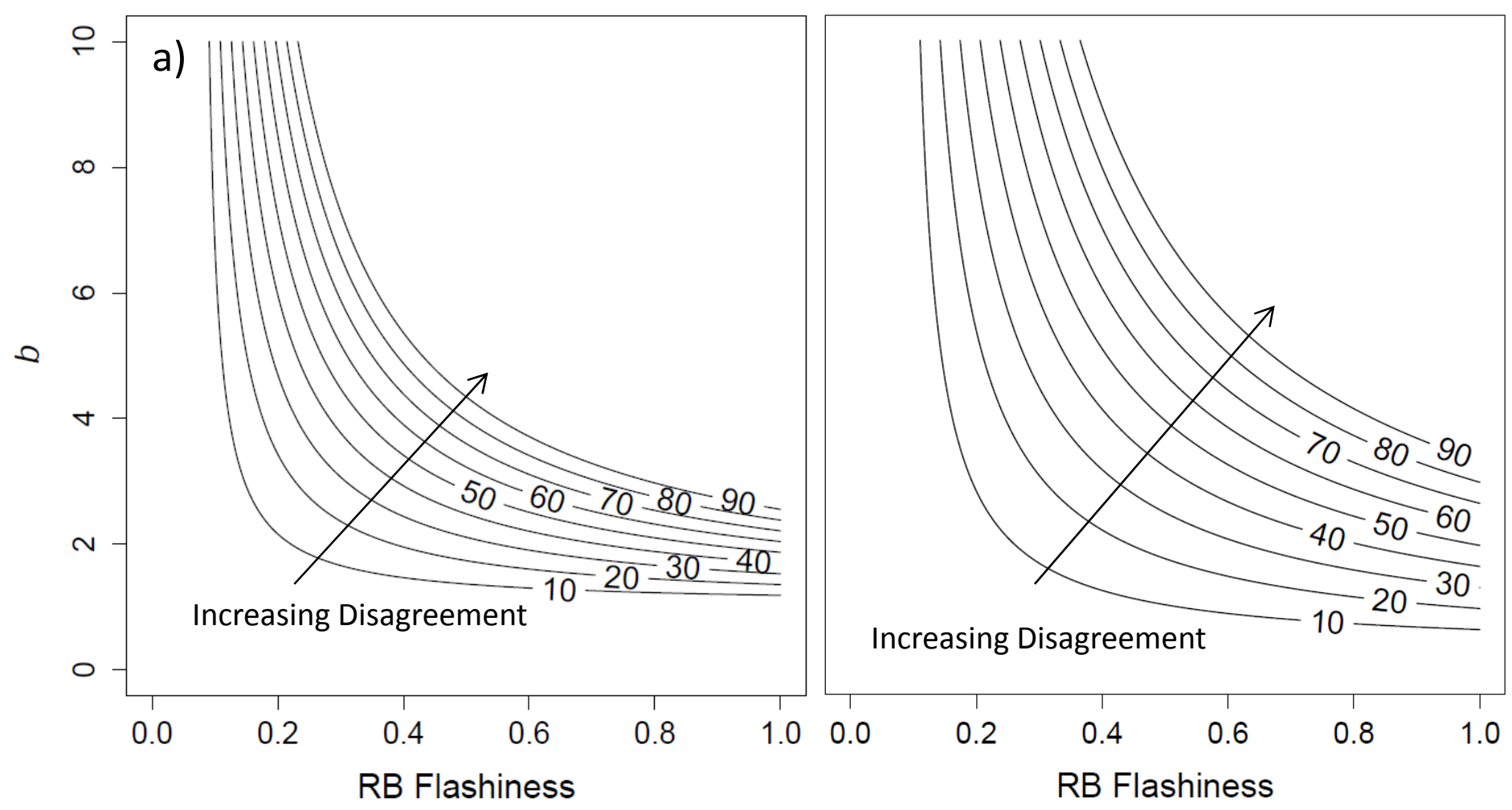

Figure 10: Percent difference in half-load discharge $\left(\mathrm{Q}_{\mathrm{s5} 5}\right)$ (values labeled at the top of contours) calculated with daily-averaged flow data. a) bedload sites b) suspended load sites. 

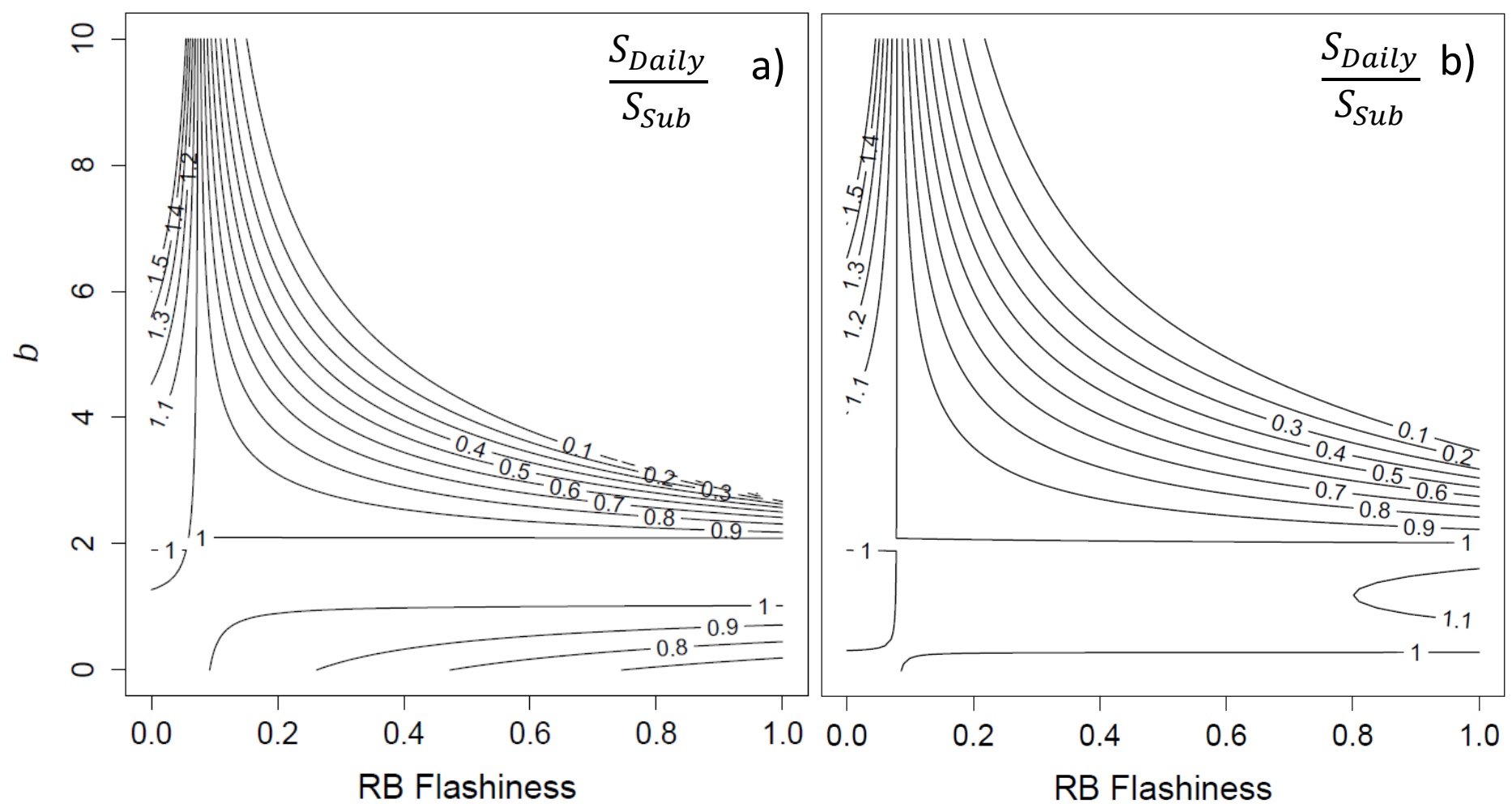

Figure 11: Ratio of design slope calculated with daily flow data $\left(\mathrm{S}_{\text {Daily }}\right)$ to the design slope calculated with subdaily flow data $\left(\mathrm{S}_{\mathrm{Sub}}\right)$ : a) bedload sites $\mathrm{b}$ ) suspended load sites 